\title{
Sudden Mono-ocular Vision Loss in An Adolescent Female: A Case Report and Review of the Literature
}

\author{
Oluwafolajimi A. Adesanya, Boluwatife A. Adewale, Ifeoluwa O. Oduguwa, and Joseph A. \\ Onumeguolor
}

\begin{abstract}
Psychogenic blindness remains a bewildering medical condition with very little information known about its exact etiology and pathophysiologic mechanism. While complaints of reduction in visual acuity are most common, occasionally patients present with complaints of total loss of vision which after extensive clinical examination and electrophysiological investigations cannot be linked to any pathology of the visual pathway. In such cases, a diagnosis of psychogenic blindness is usually considered. Here we present the case of a teenage girl who presented to the ophthalmology department with complaints of complete monocular loss of vision and was referred to the child and adolescent psychiatry team for expert management. This case showcases the importance of a multidisciplinary approach to care and importance of quick and effective referral systems in proper management of complex cases. It also provides more insight into the manner of presentation of cases of psychogenic blindness and the role of psychotherapy and counseling in its successful treatment.
\end{abstract}

Index Terms - conversion disorder; dissociative disorder; psychogenic blindness; non-organic visual loss; psychotherapy

\section{INTRODUCTION}

Psychogenic blindness remains a bewildering medical condition with very little information known about its exact etiology and pathophysiologic mechanism. It is regarded as a form of dissociative sensory loss, characterized by a unilateral or bilateral reduction in visual capacity or complete loss of vision, in the absence of a recognizable cause [1]. Dissociative disorders are conditions in which there is an unexplained disruption in the normal processes involved in the integration of neural functions of memory, identity and perception of the environment [2]. This manifests usually in an obvious, somewhat unnatural disconnect between the normal senses of perception and the ability of the higher centers of the brain to interpret the information it receives from the organs of sensation. Some of the most common presentations of this condition include claims of blindness, deafness, paralysis, loss of speech and even fugue states [3]. The ICD-10 diagnostic criteria places this class of conditions under the broad group of Neurotic,

Published on May 30, 2020.

Oluwafolajimi A. Adesanya, Department of Psychiatry, College of Medicine, University of Ibadan, Ibadan, Nigeria.

(corresponding e-mail: folajimiadeanya@gmail.com)

Boluwatife A. Adewale, Department of Psychiatry, College of Medicine, University of Ibadan, Ibadan, Nigeria

Ifeoluwa O. Oduguwa, Department of Psychiatry, College of Medicine, University of Ibadan, Ibadan, Nigeria

Joseph A. Onumeguolor, Department of Psychiatry, College of Medicine, University of Ibadan, Ibadan, Nigeria.
Stress-related and Somatoform disorders [1], while the DSM-IV prefers to refer to them as 'conversion disorders' [1]; this is because they are thought to be somatic manifestations of a more complex psychological disturbance. Due to their rare nature of occurrence, only a handful of cases have been reported, more so from lowresource environments such as: South West Nigeria, where such cases either end up unreported or dismissed to have underlying spiritual inclinations. In line with the CARE criteria, we present a case of a 15-year old girl who presented to our centre with acute, monocular loss of vision. The purpose of this report is to highlight the manner of presentation and provide more insight into the role of psychological intervention in the treatment of a case of nonorganic visual loss.

\section{CASE REPORT}

A 15-year old high school student presented to the ophthalmology clinic with a history of sudden unilateral loss of vision in her left eye with concurrent poor vision in her right eye. She was a known patient of the ophthalmology department and had presented 12 months prior with complaints of blurred vision, watery ocular discharge, redness and itching, for which a diagnosis of mild allergic conjunctivitis was made. She was subsequently placed on Antallerge sterile eye drops, causing a complete remission of the ocular symptoms. A month prior to her latest presentation, she began to experience episodes of diplopia, causing her to close her eyes for several minutes untill her vision returns to normal. This happened repeatedly at home and in school, eventually catching the attention of one of her teachers who proceeded to forcefully opened her eyes, causing her significant distress in the process. A week after this incident ensued, she presented with sudden unilateral loss of vision in her left eye and poor vision in her right eye. There was an accompanying positive history of walking into unintended objects, especially at night or under decreased illumination. There was no associated history of ocular pain, ocular discharge, redness, itching, seeing flashes of bright light, floaters, halos and photophobia.

Following extensive ocular examination which yielded no pathological basis for her presentation, a diagnosis of nonorganic vision loss [NOVL] with suspicion of conversion disorder was made and she was referred to the child and adolescent psychiatry team for expert review. On clinic day, she was able enter the consulting room smoothly. She has no previous history of psychiatric evaluation and no family history of psychiatric disorders. She was well groomed, calm and cooperative with normal psychomotor activity but avoided eye contact during the course of the interview. She 
was unhappy about her visual state but expressed optimism and belief that her full vision would soon return to her. She had normal thought and perception as well as good judgment, insight and cognitive function. She was able to carry out manual tasks like picking up a pen from the table without necessarily directing her eyes towards her hands. She claims to have a good relationship with her family and her childhood history was unremarkable. The diagnosis of psychogenic blindness as a result of a possible conversion disorder was reinforced.

She was counseled on the diagnosis together with her father and reassured that her vision would return with sufficient rest and social support. The possibility of pretending was debunked and her family was advised to avoid negative emotions or comments. About 2 weeks following the counseling, she had regained her vision completely.

\section{DISCUSSION}

According to a 2013 World Health Organization (WHO) fact sheet, visual function is defined in four levels - normal, moderate visual impairment, severe visual impairment and blindness. [4] The most common causes of visual impairment, representing about $50 \%$ of all forms of blindness in the developing world is cataract. In low-income and lower middle-income countries particularly in SubSaharan Africa, the causes of avoidable blindness include: cataract $(50 \%)$, glaucoma $(15 \%)$, corneal opacities $(10 \%)$, trachoma $(6.8 \%)$, congenital blindness $(5.3 \%)$ and onchocerciasis (4\%) [5]. Structurally therefore, we can say that the common causes of monocular visual loss can arise due to a pathology in any of the ocular components including: cornea, lens, anterior chamber and retina; or from neurological structures serving the eye, including: optic nerve/chiasm.

Psychogenic blindness as a term refers to a symptomatic loss of vision which cannot be attributed to any ocular or non-ocular pathology of the visual pathway. Other terminologies that have been used to describe this concept in literature include: non-organic blindness, functional blindness, hysterical blindness, conversation syndrome and malingering [6]. In a case reported by Dutta et al, psychogenic blindness was described as a form of dissociative sensory loss, characterized by a unilateral or bilateral reduction in visual capacity or complete loss of vision, in the absence of a recognizable cause [1]. It has been estimated that just about $1 \%$ of blindness cases presenting to ophthalmologists are a result of non-organic causes [1], further emphasizing the rarity of this presentation. About $36-80 \%$ of cases involve reports of reduction of visual acuity rather than complete loss of vision, while on its epidemiology; psychogenic blindness is a more common presentation among younger age groups, particularly from the female gender [7]. In our reported case, our patient is a 15-year old girl.

The etiology as well as the pathogenesis of non-organic visual loss is not well understood; however, current literature posits that the signs are a result of a disturbance to higher cortical structures concerned with sensory awareness [8]. This kind of disturbance may result from a conversion or somatization disorder, both in which the signs occurs as a physical symptom in response to a psychological distress. However, somatization disorders usually affect several organ systems and the symptoms tend to run a more chronic course than in conversion disorders. Another literature published in 2011 associated the symptoms with measurable neural patterns, involving attentional mechanisms [9]. In our patient, there was a previous history of ocular symptoms of mild allergic conjunctivitis for which she had been undergoing therapy and we believe this coupled with the distressing event of her eyes being forcefully opened by her teacher may have precipitated her presentation with nonorganic visual complaints.

The first step to making a diagnosis of psychogenic blindness is a failure to identify any pathology in the visual pathway following extensive clinical examination with or without electrophysiological investigations. Other findings that buttress the diagnosis include: smooth entrance into the consultation room, failure to direct eyes towards hands during tasks, flinching with increased illumination and an intact menace reflex [8]. In addition, an underlying history of traumatic psychological event, generalized anxiety disorder or delusions of guilt/worry have all been identified as possible precipitating factors for a conversion or somatization disorder, manifesting as non-organic vision loss [8]. Our patient had smooth entrance into the consultation room as well as a history of forceful opening of her eyes prior to onset of symptoms.

It is important to note that although malingering has been erroneously used in some literature as a synonym for psychogenic blindness, there is a fundamental difference between both diagnoses. In malingering, the subject does not experience his/her symptoms but feigns them for the purpose of secondary gain, which often times may mean: compensation claims and avoidance of military service [10]. Due to the potential economic and political impacts of such pretence, it is important that a physician is able to distinguish cases of true visual loss from malingering. A very good way to achieve this distinction is through the 'forced choice technique', which is performed by asking the patient to make a series of successive two-alternative judgments presented in a random manner. In a case of true blindness, the laws of probability dictates that approximately $50 \%$ of the answers will be correct, while a malingerer will go an extra mile to provide false answers in a bid to support his/her claims [8].

Some other clinical techniques used to expose intact vision include: spinning a vertically striped surface will elicit an optokinetic nystagmus in a malingerer; also, having the patient stare at a large moving mirror irresistibly compels them to follow their image with their eyes, except in a patient who is actually blind [1]. Some further techniques are described in the table below (Table 1); however, it should be noted that not all the tests are required before making a diagnosis of psychogenic blindness. These techniques are classified based on their mechanism into either: those that achieve visual acuity without the patient being aware (Group A), those that demonstrate inconsistency in patient claims (Group B) and those that objectively measure the validity of patient responses to visual stimuli (Group c) [6]. 
TABLE I: TECHNIQUES FOR EVALUATING COMPLAINTS OF NON-ORGANIC VISUAL LOSS [6]

\begin{tabular}{|c|c|c|}
\hline Group & Test & Technique \\
\hline \multirow[t]{3}{*}{ A } & Fogging test & $\begin{array}{l}\text { This is performed by placement of } \\
\text { plus lenses of increasing power } \\
\text { behind the normal eye while testing } \\
\text { the vision. Once visual acuity is } \\
\text { reached, the affected eye is occluded, } \\
\text { and the patient is asked to read the } \\
\text { chart again. A fogging effect of the } \\
\text { plus lens will lead to reduced acuity in } \\
\text { the normal eye implying that the } \\
\text { patient was actually reading from his } \\
\text { affected eye. }\end{array}$ \\
\hline & Polaroid test & $\begin{array}{l}\text { The patient wears polarized glasses } \\
\text { while looking at letters that the } \\
\text { examiner can selectively make visible } \\
\text { to either or both eyes }\end{array}$ \\
\hline & Duochrome test & $\begin{array}{l}\text { The use of spectacles- green in one } \\
\text { eye and red in the other. The patient } \\
\text { is asked to look at a screen that has } \\
\text { letters visible in one eye and invisible } \\
\text { in another. }\end{array}$ \\
\hline \multirow[t]{2}{*}{$\mathrm{B}$} & $\begin{array}{l}\text { Pupillary reaction } \\
\text { test }\end{array}$ & $\begin{array}{l}\text { Test by swinging light method to } \\
\text { assess if there is asymmetric optic } \\
\text { neuropathy/a relative afferent pupil } \\
\text { defect. Positive test is when pupils of } \\
\text { both eyes constrict to light } \\
\text { stimulation to either eye }\end{array}$ \\
\hline & Stereopsis test & $\begin{array}{l}\text { Assessment of binocular vision and } \\
\text { stereopsis through a Titmus stereo } \\
\text { test by showing series of images to } \\
\text { each eye through polarized glasses }\end{array}$ \\
\hline \multirow[t]{2}{*}{$\mathrm{C}$} & $\begin{array}{l}\text { Visual evoked } \\
\text { potential test }\end{array}$ & $\begin{array}{l}\text { Assessment of the visual pathways by } \\
\text { placing electrodes to the occipital } \\
\text { area and measuring the time taken } \\
\text { for a visual stimulus to reach the } \\
\text { occipital cortex. }\end{array}$ \\
\hline & Electroretinography & $\begin{array}{l}\text { Assessment of retinopathies by } \\
\text { measuring electrical activity in } \\
\text { response to light stimulus through } \\
\text { electrodes in corneal contact lenses. }\end{array}$ \\
\hline
\end{tabular}

The cornerstone of treatment for psychogenic blindness is reassurance by the physician that no ocular or neurologic pathology exists and vision is expected to return soon. This should be followed by an explanation of the natural history of non-organic visual loss while stressing the need for adequate rest and social support for the patient [1]. The use of placebo therapies in form of eye drops or spectacles are no longer recommended as they have been said to undermine the reassurance given by the physician [6]. Negative emotions such as accusations of pretending should be avoided by family members and they should also be counseled against enforcing punitive measures on the patient [1]. All these measures were employed in the treatment of our patient.

By using the measures described above, between $45 \%$ and $78 \%$ of patients experience complete resolution of their symptoms with return of normal vision. Some good prognostic factors include: young age and absence of comorbid psychiatric conditions [10].

\section{CONCLUSION}

A case of sudden loss of vision which cannot be traced to any organic cause could very well be one of psychogenic blindness. As we have depicted in this report, reassurance and psychotherapy in addition to social support is often sufficient therapy in most cases.

\section{REFERENCES}

[1] Dutta A, Poudel R, Thapa L, Pokhrel B. Psychogenic blindness: A rare presentation. J Psychiatr Assoc Nepal. 2014 Jan 29;2(2):49-51.

[2] Sadock B, Sadock V. Synopsis of Psychiatry. In: Dissociative Disorders. 10th ed. Philadelphia: Lippincott Williams and Wilkins; 2007. p. 665-79.

[3] Brandenburg S, Hendriks A. Psychogenic Blindness: A Strategic Model in Two Races. In: Paper presented at 7th General Assembly ICEVI-European Conference. Dublin; 2009. Available from: http://www.icevi-europe.org/dublin2009/

[4] Mulugeta S, Tesfay K, Frank R, Gruber-Frank C. Acute loss of vision in a young woman: a case report on psychogenic blindness. Ethiop J Health Sci. 2015 Jan 1;25(1):99-104.

[5] Pascolini D, Mariotti SP. Global estimates of visual impairment: 2010. Br J Ophthalmol. 2012 May;96(5):614-8.

[6] Halawani MS. Interesting case of sudden unilateral blindness in a teenager: role of psychological intervention in psychogenic visual loss. Int J Adv Med. 2019 May 24;6(3):947.

[7] Kathol RG, Clancy J. Functional visual loss: A true psychiatric disorder? Psychol Med. 1983;13(2):307-14.

[8] Beatty S. Psychogenic medicine: Non-organic visual loss. Postgrad Med J. 1999 Apr 1;75(882):201-7.

[9] Schoenfeld MA, Hassa T, Hopf J-M, Eulitz C, Schmidt R. Neural correlates of hysterical blindness. Cereb Cortex. 2011;21(10):23948.

[10] Keltner JL, May WN, Johnson CA, Post RB. The California Syndrome: Functional visual complaints with potential economic impact. Ophthalmology. 1985;92(3):427-35. 